Águas Subterrâneas (2017) 31(1):117-133.

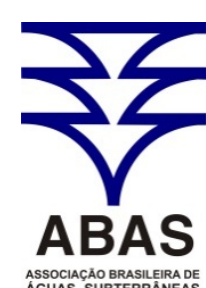

www.abas.org

\title{
RETARDAMENTO E DISPERSÃO HIDRODINÂMICA DE COBRE, POTÁSSIO E CLORETO EM SOLOS RESIDUAIS DO SUBGRUPO ITARARÉ NO ESTADO DE SÃO PAULO
}

\author{
RETARDATION AND HYDRODYNAMIC DISPERSION OF POTASSIUM, \\ COPPER AND CHLORIDE IN ITARARE SUBGROUP RESIDUAL SOILS IN \\ THE STATE OF SAO PAULO
}

\author{
Juliana Broggio Bassoํㅜㄹ Chang Hung Kiang ${ }^{1}$
}

Artigo recebido em: 31/05/2016 e aceito para publicação em: 03/01/2017.

DOI: http://dx.doi.org/10.14295/ras.v31i1.28638

\begin{abstract}
Resumo: Contaminantes inorgânicos como $\mathrm{Cu}^{2+}, \mathrm{K}^{+}$e $\mathrm{Cl}^{-}$são comuns em resíduos urbanos, industriais e/ou rurais, de forma que o entendimento do comportamento desses íons no solo é importante na gestão de áreas contaminadas. Neste estudo, foram determinados o coeficiente de dispersão hidrodinâmica $\left(D_{h}\right)$ e o fator de retardamento $\left(R_{d}\right)$ dessas espécies químicas em solos residuais arenosos e argilosos do Subgrupo Itararé, coletados nos municípios de Mogi Mirim e Capivari, região leste do estado de São Paulo. Experimentos de laboratório foram feitos com percolação de soluções aquosas de cloretos de potássio e de cobre, em diferentes concentrações, em colunas de solo saturado e regime de fluxo permanente. Curvas de Chegada (BTC) foram geradas a partir dos ensaios, obtendo-se os parâmetros de transporte a partir de ajuste numérico com o programa STANMOD. A análise de mudanças mineralógicas e de precipitados nas colunas de solos foi efetuada por meio de microscopia eletrônica de varredura. O fator de retardamento para os cátions analisados variou entre 9 e 3,9 no solo arenoso e entre 5,7 e 3,5 no solo argiloso; o cloreto apresentou $\mathrm{R}_{\mathrm{d}}$ entre 2,9 e 2,4 no solo arenoso e entre 4,6 e 2,5 no solo argiloso. O coeficiente de dispersão hidrodinâmica apresentou pouca variação entre os solos arenoso e argiloso, com valores entre $0,31 \mathrm{~cm}^{2} / \mathrm{min}$ e $0,02 \mathrm{~cm}^{2} / \mathrm{min}$ para os cátions; já o cloreto apresentou $\mathrm{D}_{\mathrm{h}}$ superior no solo argiloso $(0,11$ $\mathrm{cm}^{2} / \mathrm{min}$ e $\left.0,007 \mathrm{~cm}^{2} / \mathrm{min}\right)$ que no solo arenoso $\left(0,04 \mathrm{~cm}^{2} / \mathrm{min}\right.$ e $\left.0,006 \mathrm{~cm}^{2} / \mathrm{min}\right)$. Os ensaios de fluxo mostraram que a retenção iônica foi fortemente influenciada pelo volume de poros no solo e pela velocidade de fluxo. As análises mineralógicas das amostras percoladas não mostraram mudanças significativas e nem formação de precipitados.
\end{abstract}

Palavras-chave: Transporte de contaminante. Ensaio de coluna. Solos tropicais.

Abstract: Hydrodynamic dispersion coefficient $\left(\mathrm{D}_{\mathrm{h}}\right)$ and the retardation factor $\left(\mathrm{R}_{\mathrm{d}}\right)$ to chemical species of $\mathrm{K}^{+}$, $\mathrm{Cu}^{2+}$ and $\mathrm{Cl}^{-}$were evaluated in sandy and clay-rich residual soils of Itarare Subgroup, collected from Mogi Mirim and Capivari counties located in the eastern region Sao Paulo State. Laboratory tests were carried out percolating potassium chloride and copper chloride solutions of variable concentrations $(250 \mathrm{mg} / \mathrm{L}, 500 \mathrm{mg} / \mathrm{L}$ and $1000 \mathrm{mg} / \mathrm{L}$ of $\mathrm{K}^{+}$and $\mathrm{Cu}^{2+}$ ), through saturated soil columns at steady-state flux. Breakthrough curves (BTC) were constructed and transport parameters were calculated by fitting theoretical curve to the experimental data using the STANMOD software. Mineralogical alterations and precipitates were examined in soil samples using scanning electronic microscope. The calculated $\mathrm{R}_{\mathrm{d}}$ for cations ranged from 9 to 3.9 in sandy soil and from 5.7 to 3.5 in clay-rich soil. For chloride it varied from 4.6 to 2.4. Hydrodynamic dispersion coefficients showed values ranging from 0.02 $\mathrm{cm}^{2} / \mathrm{min}$ to $0.31 \mathrm{~cm}^{2} / \mathrm{min}$ for cations and from $0.01 \mathrm{~cm}^{2} / \mathrm{min}$ e $0.11 \mathrm{~cm}^{2} / \mathrm{min}$ for chloride. The column tests showed that ionic retention was highly influenced by pore volume on soil, and by flux velocity. Mineralogical analysis of the percolated soil samples did not indicate dissolution and precipitation of minerals.

Keywords: Contaminant transport. Column test. Tropical soils.

\section{INTRODUÇÃO}

Atualmente no Brasil existe carência na aquisição de parâmetros de transporte e retenção de contaminantes, tanto orgânicos como inorgânicos. Os contaminantes inorgânicos estão comumente presentes em resíduos urbanos, industriais e rurais sob a

1 Universidade Estadual Paulista “Júlio de Mesquita Filho” (UNESP). E-mails: (julibb@rc.unesp.br, chang@rc.unesp.br) 
forma de íons e compostos. Dentre os íons estudados, o cobre apresenta maior restrição à saúde humana, com valores orientadores de $35 \mathrm{mg} / \mathrm{kg}$ para solo (VRQ - valor de referência de qualidade CETESB, 2014) e de 2 mg/L para água subterrânea (CETESB, 2014; CONAMA, 2009). As fontes de contaminação por cobre são encontradas em atividades de mineração e fundição, em fertilizantes, fungicidas e biosólidos utilizados na agricultura e em lodos de estações de tratamento de água. O potássio não apresenta valores regulamentadores, e seu acúmulo pode ocorrer pela aplicação e infiltração de vinhaça de cana-de-açúcar e de insumos agrícolas, como fertilizantes (HASSUDA, 1989; BRITO et al., 2005; BEBÉ et al., 2009).

A concentração de cloreto em águas de abastecimento público, segundo a Portaria 2914/2011 do Ministério da Saúde, atende ao padrão de potabilidade quando inferior a 250 $\mathrm{mg} / \mathrm{L}$. Diversos são os efluentes industriais que apresentam concentrações de cloreto elevadas, como os da indústria do petróleo, de algumas indústrias farmacêuticas e de curtumes.

Os efeitos adversos dessas espécies químicas ao meio ambiente ocorrem principalmente quando sua quantidade excede a máxima capacidade de retenção do solo ou sua absorção pelas plantas, tornando-se lixiviáveis por águas subterrâneas ou superficiais. Por ser um metal pesado, o cobre causa maior preocupação, pois sua ingestão em altas concentrações pode acarretar irritação e corrosão da mucosa, problemas hepáticos, renais e irritação do sistema nervoso central.

A utilização de soluções contendo os íons $\mathrm{Cu}^{2+}, \mathrm{K}^{+}$e $\mathrm{Cl}^{-}$foram também estudadas por Boff (1999), Leite (2000), Basso (2003) e Silva (2005), por meio de ensaios de percolação em colunas compactadas de solos residuais das formações Serra Geral, Botucatu e misturas de solos, o que permitiu a comparação dos parâmetros de transporte e retenção com os solos do Subgrupo Itararé.

$\mathrm{O}$ fator de retardamento $\left(\mathrm{R}_{\mathrm{d}}\right)$ é um parâmetro empírico comumente usado em modelos de transporte para descrever as interações químicas entre contaminantes e materiais geológicos, como solos, sedimentos e rochas. Em geral é determinado sob condições de fluxo, por meio da estimativa do tempo de residência do contaminante no solo. Inclui processos sorcivos, tais como adsorção e absorção, troca iônica e precipitação. O coeficiente de dispersão hidrodinâmica $\left(\mathrm{D}_{\mathrm{h}}\right)$ é causado pelo espalhamento do soluto em seu percurso no meio poroso; envolve mecanismos de dispersão mecânica (diferentes velocidades dos solutos nos canais dos poros) e de difusão molecular (migração de solutos das zonas de maior concentração para as de menor concentração) (FREEZE e CHERRY, 1979; VAN GENUCHTEN, 1986; SHAKELFORD, 1993; EPA, 1999).

Os solos arenosos são os mais suscetíveis à ocorrência de contaminação devido à alta condutividade hidráulica, com valores entre $10^{-1} \mathrm{~cm} / \mathrm{s}$ a $10^{-4} \mathrm{~cm} / \mathrm{s}$, e à baixa capacidade de reter íons (FREEZE e CHERRY, 1979). Esse é o caso dos solos residuais arenosos do Subgrupo Itararé, que possuem grande importância como fonte de suprimento de água para consumo humano e industrial na região leste do estado de São Paulo.

De acordo com Petri et al. (1996), a importância do Subgrupo Itararé como aquífero vem da necessidade local de abastecimento de água para cidades da bacia hidrográfica do Médio Tietê (SP); poços tubulares perfurados na região de Capivari e Rafard apresentam capacidade específica média de $0,65 \mathrm{~m}^{3} / \mathrm{h} / \mathrm{m}$ e profundidade média dos poços de 272,23 m.

Os solos argilosos são conhecidos por apresentarem baixa condutividade hidráulica saturada, com ordem de grandeza de $10^{-4} \mathrm{~cm} / \mathrm{s}$ a $10^{-9} \mathrm{~cm} / \mathrm{s}$ (FETTER, 2001). No entanto, alguns solos argilosos tipicamente lateríticos também podem ser altamente permeáveis, isto é, quando estruturados e com influência da macroporosidade. Esses solos argilosos apresentam características como alta quantidade de agregados (peds) com estrutura porosa e são constituídos predominantemente de argilominerais, cime-nto de $\mathrm{Fe}_{2} \mathrm{O}_{3}$ e $\mathrm{Al}_{2} \mathrm{O}_{3}$ 
e alto teor de umidade. A estrutura desses solos é responsável por sua elevada permeabilidade natural quando percolados por água.

O escasso conhecimento do comportamento dos solos tropicais frente a soluções contaminantes faz com que a aplicação de técnicas de remediação, a estimativa de risco ambiental e a modelagem matemática de plumas, fundamentadas em experiências e parâmetros de solos de clima temperado, sejam por vezes incorretas ou deficientes. Neste sentido, o trabalho visa contribuir, na prática, com a obtenção de parâmetros de transporte e retenção dos íons $\mathrm{K}^{+}, \mathrm{Cu}^{2+}$ e $\mathrm{Cl}^{-}$ em solos residuais arenosos e argilosos do Subgrupo Itararé, por meio de ensaios de percolação em colunas saturadas em regime permanente, modelagem matemática de Breakthrough Curves (BTC) e análises mineralógicas, com vistas a investigar os fatores associados à dispersão desses íons em solos.

\section{MATERIAIS E MÉTODOS}

\subsection{Propriedades dos Solos}

Os solos arenosos e argilosos foram coletados em cortes de rodovias e constituem materiais intempéricos de rochas do Subgrupo Itararé presentes na região leste do Estado de São Paulo.

O solo arenoso foi amostrado em um talude lateral da rodovia SP-340, no município de Mogi Mirim (4658’58” W / $22^{\circ} 27^{\prime} 28^{\prime \prime} \mathrm{S}$ ), e corresponde a uma rocha alterada, predominantemente arenosa, consolidada, com coloração avermelhada clara e com feições erosivas de ravinamento superficial no talude. O solo argiloso foi amostrado em um talude lateral da rodovia do Açúcar, SP-308, no município de Capivari (4723’59” W / 2305'04” S), e corresponde a um solo residual jovem, parcialmente consolidado, argilo-siltoso, com coloração avermelhada variegada e porções brancas; talude com feições erosivas de ravinamento superficial. A unidade litoestratigráfica do Subgrupo Itararé, de idade permo-carbonífera é constituída por uma associação de arenitos, siltitos, argilitos, conglomerados, ritmitos e diamictitos, em geral de origem flúvio-glacial na região norte da Bacia Sedimentar do Paraná. Apresenta significativa extensão territorial $\left(1,48 \times 10^{4} \mathrm{~km}^{2}\right)$ aflorante na Bacia do Paraná e na região leste do estado constitui importante aquífero, utilizado como fonte de abastecimento de água para consumo humano. Segundo LEVANTA-MENTO PEDOLÓGICO SEMIDETALHA-DO DO ESTADO DE SÃO PAULO (1984), na área de abrangência deste estudo, a unidade apresenta solo predominantemente arenoso, com granulométria fina a média, classificado como latossolo vermelho-amarelo (LVA), e associação com argissolo vermelho-amarelo (PVA) nas porções mais siltícas. A Figura 1 mostra a área de exposição do Subgrupo Itararé no Estado de São Paulo e os municípios onde foram coletadas as amostras.

Foram coletadas amostras de solos deformadas e indeformadas no intervalo entre 1 e 2 metros de profundidade, despre-zandose a cobertura superficial a fim de atenuar os efeitos de substâncias como matéria orgânica e resíduos de ação antrópica.

A amostragem de solo indeformado teve o objetivo de determinar os índices físicos de campo, principalmente densidade seca do solo $\left(\rho_{\mathrm{d}}\right)$ e umidade $(\mathrm{w})$, para assim reproduzir esses valores na compactação dos solos nas colunas de PVC, posteriormente utilizadas no ensaio de percolação. As amostras deformadas foram utilizadas como material para compactação dos diversos corpos de prova utilizados nos ensaios de percolação em colunas e também para caracterização física, físico-química e mineralógica dos solos.

A densidade seca foi determinada a partir do valor médio de três amostras indeformadas, coletadas em anéis de aço inox de $50 \mathrm{~mm}$ de diâmetro, obtendo-se os valores de $1,812 \mathrm{~g} / \mathrm{cm}^{3}$ para o solo arenoso e 1,518 $\mathrm{g} / \mathrm{cm}^{3}$ para o solo argiloso. O teor de umidade foi determinado no mesmo dia da coleta e obtido tanto nas amostras deformadas quanto nas indeformadas, a partir dos valores médios 
de três determinações em cada tipo de amostra dos solos arenoso e argiloso. A variação do teor de umidade entre as amostras indeformadas e deformadas foi de 7,13\% e $7,44 \%$ para o solo arenoso e de $17,32 \%$ e $18,79 \%$ para o solo argiloso.

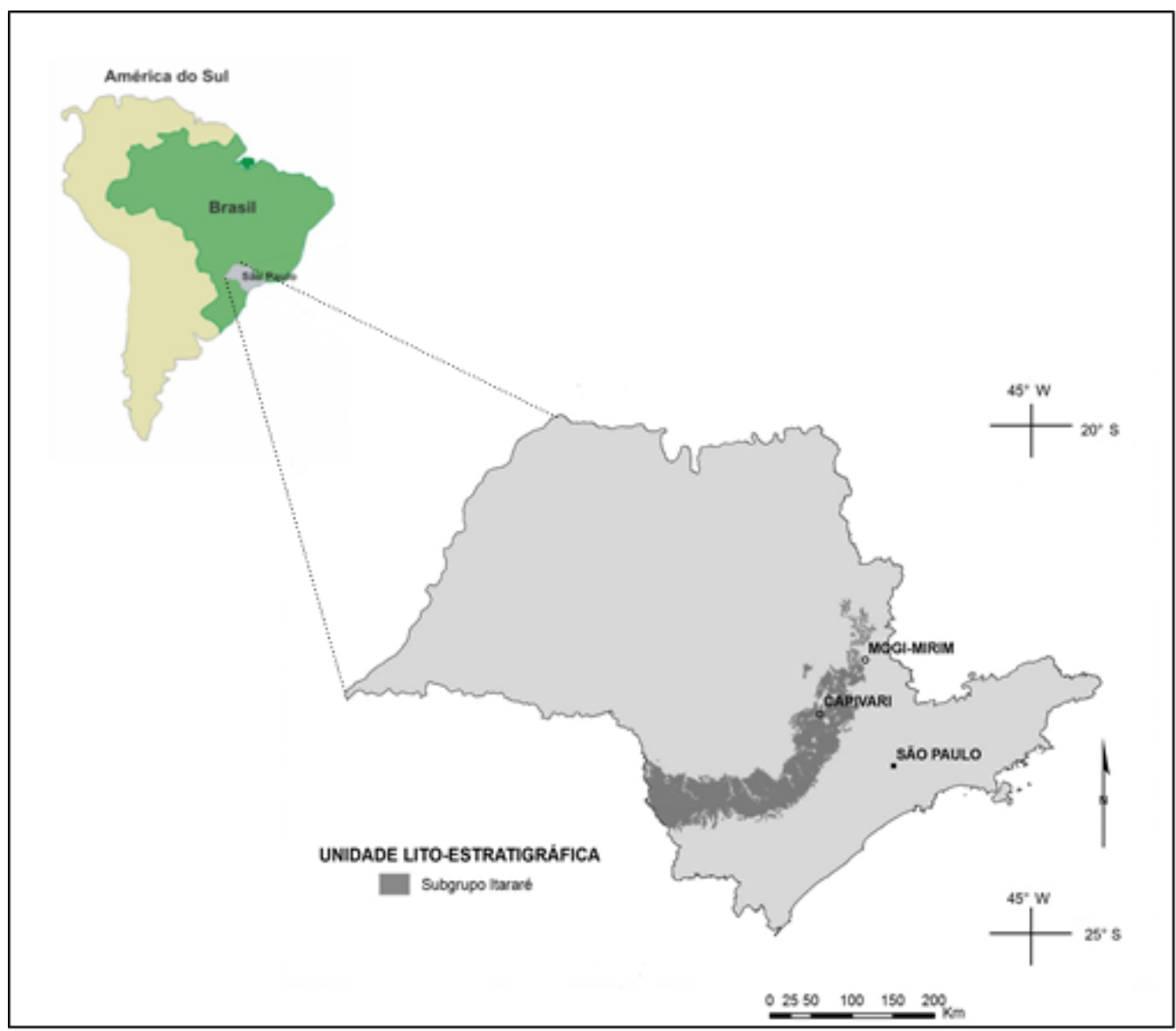

Figura 1 - Área de exposição do Subgrupo Itararé no estado de São Paulo, com indicação dos municípios - Mogi Mirim e Capivari - em que foram coletadas as amostras

Figure 1 - Itarare Subgroup outcrop area in the state of Sao Paulo, showing the municipalities of Mogi Mirim and Capivari where samples were collected.

As amostras de solos deformadas, foram levadas ao laboratório e submetidas à secagem ao ar e à sombra, destorroadas, homogeneizadas e peneiradas em malha com abertura de 4,8 mm de diâmetro, para posterior utilização na compactação das colunas.

Os ensaios utilizados na caracterização física das amostras de solos foram granulometria conjunta (ABNT - MB 32 NBR7181) e massa específica sólida dos solos (ASTM - D854).

Características físico-químicas como pH do solo, condutividade elétrica do extrato aquoso e Ponto de Efeito Salino Zero (PESZ) foram obtidas seguindo os procedimentos descritos por Camargo et al. (1986). A capacidade de troca catiônica e a superfície específica foram determinadas usando o método de azul de metileno, proposto por Lan (1977) e modificado por Pejon (1992). As quantidades de matéria orgânica e de óxidos e hidróxidos foram determinadas pelos métodos de Raij et al. (2001) e EMBRAPA (1997), respectivamente.

Foram utilizadas difratometria de raios-X, análise térmica diferencial (ATD) e microscopia eletrônica de varredura (MEV) para identificação da composição mineralógica das amostras de solos arenoso e argiloso.

A composição mineralógica de amostras extraídas das colunas percoladas com soluções de $\mathrm{KCl}$ e $\mathrm{CuCl}_{2}$ foi analisada 
por microscopia eletrônica de varredura e detector de energia dispersiva (Energy Dispersive X-Ray Spectroscopy - EDS). Essa análise teve por objetivo verificar mudanças microestruturais, formação de precipitados e/ ou transformações mineralógicas nas amostras percoladas.

\subsection{Soluções Percoladas}

Soluções aquosas de cloreto de cobre e de potássio, em três diferentes concentrações - $250 \mathrm{mg} / \mathrm{L}, 500 \mathrm{mg} / \mathrm{L}$ e $1000 \mathrm{mg} / \mathrm{L}$ - de íons $\mathrm{K}^{+}$e $\mathrm{Cu}^{2+}$, foram percoladas isoladamente em colunas de material arenoso e argiloso do Subgrupo Itararé. O pH dessas soluções apresentou valores mínimos e máximos de 5,1 e 6,6 para $\mathrm{KCl}$, e de 4,6 e 5,3 para $\mathrm{CuCl}_{2}$.

O potássio e o cobre das soluções iniciais e dos efluentes foram determinados por meio de Espectrofotometria de Absorção Atômica com Chama (FAAS) e por Espectrometria de Emissão Atômica com Fonte de Plasma de Argônio Induzido (ICPAES), respectivamente. O íon cloreto foi analisado por duas técnicas: cromatografia iônica (baixas concentrações) e titulação volumétrica de precipitação (altas concentrações).

\subsection{Ensaios de Percolação em Colunas}

As etapas do ensaio de percolação em colunas consistiram: (a) na compactação das colunas com os solos arenoso e argiloso separadamente, (b) na saturação com água deionizada e (c) na percolação com soluções aquosas de cloreto de cobre e de potássio separadamente.

O procedimento do ensaio consistiu na percolação de solução iônica aquosa com concentração conhecida $\left(\mathrm{C}_{0}\right)$, provinda do reservatório influente, em colunas de solos compactadas e previamente saturadas com água deionizada. Foram monitoradas periodicamente a condutividade hidráulica e as condições físico-químicas ( $\mathrm{pH}$, Eh e condutividade elétrica) durante o período de percolação com água deionizada e depois com as soluções. Amostras do reservatório efluente foram recolhidas periodicamente para determinação da concentração química dos íons (C) e para confecção das Curvas de Chegada (BTC).

Neste trabalho foi utilizado um sistema de equipamento de percolação similar ao desenvolvido por Leite (2000), com as modificações feitas por Basso (2003) e outras por Pereira (2006). Informações sobre o equipamento de percolação, projeto, construção e modificações posteriores poderão ser obtidas nesses trabalhos.

Foram efetuados ensaios de percolação em seis colunas de solo arenoso e seis colunas de solo argiloso compactadas diretamente em cilindros de PVC (15 cm de altura e $10 \mathrm{~cm}$ de diâmetro); cada coluna de solo arenoso continha 2150 g de massa de solo úmido compactado, enquanto cada coluna de solo argiloso continha 1970 g. A carga hidráulica aplicada foi de $17 \mathrm{kPa} \pm 2 \mathrm{kPa}$ nas colunas de solo saturados.

A preparação das amostras para compactação foi feita da seguinte maneira: pesou-se cerca de $2,5 \mathrm{~kg}$ de solo seco e calculou-se o volume de água a ser adicionado para atingir a umidade de campo que foi determinada previamente a partir das amostras indeformadas. Em seguida, a amostra umedecida e homogeneizada foi mantida na câmara úmida, para menor perda de água e, após 24 horas, foi determinado o teor de umidade novamente, sendo esse solo utilizado na compactação das colunas somente quando obtido valor próximo do teor de umidade de campo. A massa de solo a ser compactado na coluna de percolação foi estimada pela equação:

$$
M_{s c}=\rho_{d} V_{c}\left(1+w_{c}\right) G c
$$

onde: $\rho_{d}$ é a densidade seca do solo $\left(\mathrm{g} / \mathrm{cm}^{3}\right)$, $\mathrm{V}_{\mathrm{c}}$ volume da célula de percolação $\left(\mathrm{cm}^{3}\right), \mathrm{w}_{\mathrm{c}}$ teor de umidade de compactação (\%), Gc grau de compactação (\%).

As colunas foram compactadas com densidade seca do solo ( $\rho_{\mathrm{d} \text { compactação }}$ próxima aos valores de campo (amostras indeformadas), $1,82 \mathrm{~g} / \mathrm{cm}^{3}$ e $1,52 \mathrm{~g} / \mathrm{cm}^{3}$, e teor 
de umidade de $7,18 \%$ e $17,40 \%$ para os solos arenoso e argiloso, respectivamente.

As colunas de solo foram previamente saturadas com água deionizada: $\mathrm{pH}_{\text {médio de }}$ 5,79, com mínimo de 5,14 e máximo de 6,84, e condutividade elétrica média de $1,92 \mu \mathrm{S} / \mathrm{cm}$, com mínimo de 1,45 $\mu \mathrm{S} / \mathrm{cm}$ e máximo de 2,22 $\mu \mathrm{S} / \mathrm{cm}$. Durante essa fase, o fluxo foi aplicado no sentido ascendente para permitir uma melhor saturação e a total expulsão de ar do solo. A percolação das colunas com água deionizada foi realizada a fim de se obter: saturação de $100 \%$ do corpo de prova; lixiviação dos sais solúveis presentes no solo, de forma a reduzir a concentração iônica do líquido dos poros; vazão do efluente para atingir a condição de fluxo estacionário (steady state), na qual a condutividade hidráulica se mantém constante.

A condutividade hidráulica $(\mathrm{K})$ foi calculada a partir da equação de Darcy e referenciada à temperatura de $20{ }^{\circ} \mathrm{C}$. A temperatura local foi mantida em $21^{\circ} \mathrm{C} \pm 2$ ${ }^{\circ} \mathrm{C}$, em local climatizado, pois influencia a viscosidade dinâmica da água, interferindo diretamente na condutividade hidráulica e, quimicamente, na solubilidade, modificando a concentração dos sais, e nos mecanismos de retenção dos íons.

Em ensaios de coluna, é comum as Curvas de Chegada serem expressas em termos do fator $\mathrm{T}$, que representa a relação entre o volume de solução percolado $(V p)$ e o volume de vazios do corpo de prova $(V v)$. De acordo com Cleary (1991), o valor dos volumes de vazios percolados, para um solo saturado, pode ser representado pela equação:

$$
T=\frac{V p}{V v}=\frac{Q t}{A_{t} L n}=\frac{v t}{L}
$$

onde $Q$ é a vazão através da amostra de solo; $t$, o tempo decorrido entre uma coleta e outra do efluente; $A_{t}$, a área da seção transversal da coluna; $L$, a altura do corpo de prova; $n$, a porosidade do solo; e $v$, a velocidade linear média ou velocidade de infiltração.

O volume de vazios obtido para as colunas de solo arenoso foi de $351 \pm 1 \mathrm{~cm}^{3}$ e para as colunas de solo argiloso foi de $485 \pm 1$ $\mathrm{cm}^{3}$. O tempo para atingir as condições de estabilidade foi cerca de 10 a 13 dias de percolação com água deionizada.

Depois de atingidas as condições de estabilidade de vazão e de máxima lixiviação dos sais presentes no solo (condutividade elétrica entre $5 \mu \mathrm{S} / \mathrm{cm}$ e $3 \mu \mathrm{S} / \mathrm{cm}$ ), foi iniciada a percolação com as soluções iônicas de $\mathrm{KCl}$ e $\mathrm{CuCl}_{2}$, invertendo o fluxo para o sentido descendente.

Para o solo arenoso percolado, a coleta da solução efluente foi feita a cada volume de vazios percolado de solução contaminante $\left(\mathrm{Vv}=351 \mathrm{~cm}^{3} \pm 1 \mathrm{~cm}^{3}\right)$ do corpo de prova. Para o solo argiloso, a coleta foi feita a cada $1 / 4$ do número de volume de vazios percolados $\left(\mathrm{Vv}=122 \mathrm{~cm}^{3} \pm 2 \mathrm{~cm}^{3}\right)$, nas 10 primeiras amostragens; após, as coletas foram a cada $1 / 2$ do número de volume de vazios percolados $\left(\mathrm{Vv}=243 \mathrm{~cm}^{3} \pm 2 \mathrm{~cm}^{3}\right)$.

Para cada experimento foram elaboradas BTC em função da concentração relativa dos íons $\left(\mathrm{C} / \mathrm{C}_{0}\right)$ e do número de volume de poros percolados (T). O ensaio de coluna foi finalizado quando a concentração relativa $\mathrm{C} / \mathrm{C}_{0}=1$, ou seja, quando a concentração da solução efluente $(\mathrm{C})$ atingiu a concentração inicial influente $\left(\mathrm{C}_{0}\right)$. O fluxo e a concentração da solução influente $\left(\mathrm{C}_{0}\right)$ foram mantidos constantes durante os ensaios de colunas.

Com auxílio do programa STANDMOD (versão 2.0), desenvolvido por Simunek et al. (1999), foram calculados o fator de retardamento e o número de Peclet (P), ajustando-se uma curva teórica aos pontos experimentais pelo método de mínimos quadrados. A solução analítica de equilíbrio unidimensional da advecção-dispersão é dada pela equação:

$$
R_{d} \frac{\partial c}{\partial t}=D_{h} \frac{\partial^{2} c}{\partial x^{2}}-v \frac{\partial c}{\partial x}
$$

onde $c$ é a concentração da solução, $x$ é a distância, $t$ é o tempo, $D_{h}$ é o coeficiente de dispersão hidrodinâmica, $v$ é a velocidade linear média (fluxo de água, $q$, dividido pela porosidade total, $\mathrm{n}$ ), e $R_{d}$ é o fator de retardamento, definido como: 


$$
R_{d}=1+\frac{\rho_{d}}{n} K_{d}
$$

onde $\rho_{d}$ é a densidade do solo seco e $K_{d}$ é coeficiente de distribuição linear.

O coeficiente de dispersão hidrodinâmica foi calculado pela equação:

$$
D_{h}=\frac{v L}{P}
$$

onde $L$ é o comprimento da coluna e $P$ é o número de Peclet.

Esta formulação teórica baseia-se no princípio da conservação de massa, em que o fluxo se dá em uma única direção, através de meios porosos, considerando-se um meio homogêneo, isotrópico, não deformável, e transporte condicionado por fluido incompressível em regime de fluxo constante.

\section{RESULTADOS E DISCUSSÕES}

As características físicas, físicoquímicas e mineralógicas dos solos estudados estão apresentadas na Tabela 1 . Os valores de análise granulométrica conjunta dos solos arenoso e argiloso estão consistentes com o esperado; enquanto no solo arenoso predominaram areias média e fina, totalizando cerca de $70 \%$ de fração areia, no solo argiloso predominaram argila e silte, com apenas $28 \%$ de fração areia.

Tabela 1 - Características físicas, físico-químicas e mineralógicas dos solos arenoso e argiloso do Subgrupo Itararé, anteriormente à percolação de soluções iônicas em colunas

Table 1 - Physical, physical-chemical and mineralogical characteristics of sandy and clay soils of the Itarare Subgroup, prior to percolation in columns

\section{Propriedades}

Argila (\%) $(<0,002 \mathrm{~mm})$

Silte (\%) $(0,002-0,075 \mathrm{~mm})$

Areia fina (\%) $(0,075-0,42 \mathrm{~mm})$

Areia média (\%) $(0,42-2 \mathrm{~mm})$

Areia grossa (\%) (2-4,8mm)

$\rho_{\mathrm{s}}\left(\mathrm{g} / \mathrm{cm}^{3}\right)$

CTC (meq/100g)

$\mathrm{SE}\left(\mathrm{m}^{2} / \mathrm{g}\right)$

pH do solo em $\mathrm{H}_{2} \mathrm{O}$

$\mathrm{pH}$ do solo em $\mathrm{KCl}$

$\triangle \mathrm{pH}$

$\mathrm{CE}(\mu \mathrm{S} / \mathrm{cm})$

Matéria orgânica (\%)

PESZ

Óxidos: Fe, Mn, Si, Al, Ti (\%)

Mineralogia da fração fina

$(<0,037 \mathrm{~mm})$

Solos

Arenoso

10

15,7

20,7

48,4

5,2

2,665

2,0

16,3

5,55

4,26

$-1,29$

20,3

0,37

2,8

1,19; 0,02; 5,5; 5,98; 0,09

caulinita, ilita-esmectita,
Argiloso

37,3

34,4

20,0

7,7

0,6

2,710

2,8

22,0

5,79

4,34

$-1,45$

19,1

1,02

4,1

6,0; 0,01; 15,5; 17,2; 0,23

caulinita, ilita-esmectita, óxidos $\mathrm{Fe}, \mathrm{Al}$ e Ti

CTC - Capacidade de troca catiônica; SE - Superfície específica; PESZ - Ponto de efeito salino zero; $\Delta \mathrm{pH}=\mathrm{pH}_{\mathrm{KCl}}$ - $\mathrm{pH}_{\mathrm{H} 2 \mathrm{O}}$;

$\rho_{\mathrm{s}}$ - Massa específica dos sólidos; CE - Condutividade elétrica do extrato aquoso.

Os solos estudados são ácidos, cauliníticos, com baixa capacidade de troca catiônica, baixo teor de matéria orgânica e cargas elétricas variáveis no solo, predominando as negativas. $\mathrm{O}$ solo argiloso apresentou as maiores concentrações de $\mathrm{Fe}, \mathrm{Al}$ e Ti, elementos comuns em solos lateríticos, caracterizando-o como mais suscetível à mudança de cargas elétricas nas partículas sólidas, influenciado pelas condições de $\mathrm{pH}$ do meio.

As colunas de solo argiloso apresentaram valores médios de condutividade hidráulica superiores às das colunas de solo arenoso (Tabela 2). Dentre os fatores atribuídos a esse fato deve-se a influência da densidade do solo, com valor médio maior no solo arenoso $\left(1,82 \mathrm{~g} / \mathrm{cm}^{3}\right)$ do 
que no argiloso $\left(1,52 \mathrm{~g} / \mathrm{cm}^{3}\right), \quad$ o que proporcionou um aumento no volume de vazios no solo argiloso (Tabela 2). Também verifica-se que a fração fina do solo argiloso do Subgrupo Itararé é dividida entre os teores da fração silte (34\%) e da fração argila (37\%), diferentemente de solos em que predominam granulometria argilosa, como por exemplo os solos da Formação Serra Geral.

Tabela 2 - Características físicas e hidráulicas das colunas de solos compactados para os ensaios de percolação Table 2 - Physical and hydraulic characteristics of compacted soils columns for the percolation tests

\begin{tabular}{|c|c|c|}
\hline \multirow[t]{2}{*}{ Propriedades } & \multicolumn{2}{|c|}{ Colunas solos } \\
\hline & Arenoso & Argiloso \\
\hline $\mathrm{W}_{\mathrm{c}}(\%)$ & 7,18 & 17,40 \\
\hline$\rho_{d}\left(g / \mathrm{cm}^{3}\right)$ & 1,812 & 1,518 \\
\hline e & 0,47 & 0,79 \\
\hline n (\%) & 31,8 & 44,0 \\
\hline$\rho_{\mathrm{d} \text { compactação }}\left(\mathrm{g} / \mathrm{cm}^{3}\right)$ & 1,82 & 1,52 \\
\hline Grau de compactação (\%) & 94 & 92 \\
\hline Grau de saturação (\%) & 42 & 60 \\
\hline $\mathrm{Vv}\left(\mathrm{cm}^{3}\right)$ & 351 & 485 \\
\hline $\mathrm{K}_{\text {média }}$ a $20^{\circ} \mathrm{C}(\mathrm{cm} / \mathrm{s})$ água & $9,6 \times 10^{-6}$ & $1,3 \times 10^{-5}$ \\
\hline $\mathrm{K}_{\text {média }}$ a $20^{\circ} \mathrm{C}(\mathrm{cm} / \mathrm{s})$ solução & $8,8 \times 10^{-6}$ & $1,8 \times 10^{-5}$ \\
\hline q (cm/s) água & $1,1 \times 10^{-4}$ & $1,6 \times 10^{-4}$ \\
\hline q $(\mathrm{cm} / \mathrm{s})$ solução & $9,9 \times 10^{-5}$ & $2,1 \times 10^{-4}$ \\
\hline$V_{\text {média }} \mathrm{cm} / \mathrm{s}$ & $3,4 \times 10^{-4}$ & $5,4 \times 10^{-4}$ \\
\hline
\end{tabular}

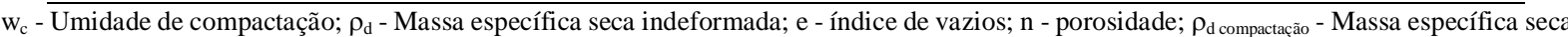
compactação; Vv - volume de vazios da coluna; K - Condutividade hidráulica; q - velocidade de Darcy; $v$ - velocidade linear média.

Valores altos de condutividade hidráulica saturada (valor médio de 1,59 x 10${ }^{3} \mathrm{~cm} / \mathrm{s}$ ) foram também observados por Soto (1999) em amostras indeformadas de solo argilo-siltoso, estruturado e com macroporosidade moderada ou média, proveniente da Formação Serra Geral, com 59\% na fração argila e $\rho_{d}$ de $1,20 \mathrm{~g} / \mathrm{cm}^{3}$. Resultados semelhantes de condutividade hidráulica média saturada, de $3,50 \times 10^{-3} \mathrm{~cm} / \mathrm{s}$, em argila arenosa (Latossolo Vermelho distrófico), foram obtidos por Oliveira et al. (2005). Em resultados de ensaios de coluna com solução de potássio $(2000 \mathrm{mg} / \mathrm{L})$ em dois solos deformados e compactados, um arenoso (Latossolo Vermelho-Amarelo) e outro argiloso (Nitossolo Vermelho), Santos et al. (2012) também obtiveram valor de q (velocidade de Darcy) superior no solo argiloso $(1,4 \mathrm{~cm} / \mathrm{min})$ em relação ao solo arenoso $(0,82 \mathrm{~cm} / \mathrm{min})$.

Silva (2005) apresentou resultados de percolação de ensaios de colunas com soluções de $\mathrm{CuCl}_{2}$, em solos saturados e compactados, provenientes das formações Serra Geral (argiloso) e Botucatu (arenoso), coletados no estado de São Paulo. Verifica-se que o valor médio de condutividade hidráulica, de 8,3 x $10^{-6} \mathrm{~cm} / \mathrm{s}$, obtido nas colunas de solo da Formação Botucatu (89\% fração areia), com $\rho_{d}$ de $1,95 \mathrm{~g} / \mathrm{cm}^{3}$, foi próximo ao valor médio de $\mathrm{K}$ obtido para as colunas de solo arenoso do Subgrupo Itararé. Já para as colunas de solo da Formação Serra Geral, o valor médio de $\mathrm{K}$ de $2,63 \times 10^{-7} \mathrm{~cm} / \mathrm{s}$ foi inferior ao valor obtido nas colunas de solo argiloso do Subgrupo Itararé (Tabela 2); devido ao $\rho_{d}$ de $1,63 \mathrm{~g} / \mathrm{cm}^{3}$ e à textura granulométrica de $51 \%$ na fração argila nas colunas de solo argiloso da Formação Serra Geral.

Nas figuras 2 e 3 são apresentadas as curvas de chegada dos íons $\mathrm{Cu}^{2+}, \mathrm{K}^{+}$e $\mathrm{Cl}^{-}$ obtidas experimentalmente para os solos arenoso e argiloso, respectivamente, além das curvas ajustadas pelo modelo numérico no STANMOD. A tabela 3 apresenta os resultados de fator de retardamento, número de Peclet e o coeficiente de dispersão hidrodinâmica dos solos arenoso e argiloso do Subgrupo Itararé para os íons $\mathrm{K}^{+}, \mathrm{Cl}^{-}$e $\mathrm{Cu}^{2+}$, a partir do ajuste do modelo numérico. Os 
parâmetros $\mathrm{P}$ e $\mathrm{R}_{\mathrm{d}}$ estão no intervalo de confiança de $95 \%$ e são mostrados com seu desvio padrão na Tabela 3.

Tabela 3 - Resultados de fator de retardamento $\left(\mathrm{R}_{\mathrm{d}}\right)$, número de Peclet $(\mathrm{P})$ e coeficiente de dispersão hidrodinâmica $\left(\mathrm{D}_{\mathrm{h}}\right)$ dos solos arenoso e argiloso do Subgrupo Itararé, para os íons $\mathrm{K}^{+}$, $\mathrm{Cl}^{-}$e $\mathrm{Cu}^{2+}$.

Table 3 - $R_{d}$ P and $D_{h}$ results from sandy and clay-rich soils of Itarare Subgroup for the ions $\mathrm{K}^{+}, \mathrm{Cl}^{-}$and $\mathrm{Cu}^{2+}$.

\begin{tabular}{|c|c|c|c|c|c|c|}
\hline \multirow[t]{3}{*}{ Colunas solos } & \multicolumn{6}{|c|}{ Ajuste do Modelo Analítico } \\
\hline & \multicolumn{2}{|c|}{$\mathbf{R}_{\mathbf{d}} \pm \mathrm{SD}^{*}$} & \multicolumn{2}{|c|}{$\mathbf{P} \pm \mathrm{SD}^{*}$} & \multicolumn{2}{|c|}{$D_{h}\left(\mathrm{~cm}^{2} / \mathrm{min}\right)$} \\
\hline & cátion & $\mathbf{C l}$ & cátion & Cl & cátion & Cl \\
\hline \multicolumn{7}{|l|}{ Arenoso } \\
\hline ITA-ARE K250 & $9,02 \pm 0,01$ & $2,94 \pm 0,03$ & $1,78 \pm 0,20$ & $15,50 \pm 1,35$ & 0,127 & 0,015 \\
\hline ITA-ARE K500 & $5,82 \pm 0,13$ & $2,67 \pm 0,04$ & $2,95 \pm 0,26$ & $10,85 \pm 1,16$ & 0,154 & 0,042 \\
\hline ITA-ARE K1000 & $5,36 \pm 0,33$ & $2,54 \pm 0,03$ & $2,45 \pm 0,58$ & $24,95 \pm 4,19$ & 0,076 & 0,007 \\
\hline ITA-ARE Cu250 & $6,47 \pm 0,43$ & $2,59 \pm 0,06$ & $2,38 \pm 0,58$ & $14,17 \pm 2,22$ & 0,211 & 0,035 \\
\hline ITA-ARE Cu500 & $5,36 \pm 0,13$ & $2,60 \pm 0,03$ & $3,67 \pm 0,38$ & $16,02 \pm 1,67$ & 0,078 & 0,018 \\
\hline ITA-ARE Cu1000 & $3,95 \pm 0,18$ & $2,39 \pm 0,03$ & $8,36 \pm 2,22$ & $30,52 \pm 3,62$ & 0,021 & 0,006 \\
\hline \multicolumn{7}{|l|}{ Argiloso } \\
\hline ITA-ARG K250 & $5,61 \pm 0,09$ & $4,32 \pm 0,08$ & $7,81 \pm 0,69$ & $11,61 \pm 1,22$ & 0,094 & 0,063 \\
\hline ITA-ARG K500 & $4,42 \pm 0,06$ & $3,48 \pm 0,02$ & $10,53 \pm 0,93$ & $19,40 \pm 0,92$ & 0,050 & 0,027 \\
\hline ITA-ARG K1000 & $3,95 \pm 0,07$ & $2,94 \pm 0,07$ & $3,13 \pm 0,20$ & $4,30 \pm 0,37$ & 0,150 & 0,109 \\
\hline ITA-ARG Cu250 & $5,70 \pm 0,17$ & $4,60 \pm 0,12$ & $6,71 \pm 1,07$ & $9,82 \pm 1,73$ & 0,043 & 0,029 \\
\hline ITA-ARG Cu500 & $5,02 \pm 0,27$ & $3,00 \pm 0,10$ & $2,44 \pm 0,40$ & $10,40 \pm 2,29$ & 0,308 & 0,072 \\
\hline ITA-ARG Cu1000 & $3,52 \pm 0,13$ & $2,47 \pm 0,02$ & $5,74 \pm 0,95$ & $26,19 \pm 2,11$ & 0,031 & 0,007 \\
\hline
\end{tabular}

Todos os íons percolados na forma de soluções aquosas, nos ensaios de coluna, foram sorvidos (Figuras 2 e 3 ). No solo argiloso, o $\mathrm{Cu}^{2+}$ foi o elemento mais sorvido; no solo arenoso, o $\mathrm{K}^{+}$apresentou maiores valores de $R_{d}$ (entre 9 e 5,3). Nos dois solos estudados, os valores de $R_{d}$ encontrados são significativos, principalmente nas concentrações de $250 \mathrm{mg} / \mathrm{L}$ e $500 \mathrm{mg} / \mathrm{L}$ nas solu-ções contendo potássio e cobre.

De maneira geral, verifica-se que o formato das curvas de distribuição dos íons está coerente com os resultados de fluxo e sorção. Observa-se a alta mobilidade do cloreto e sua baixa sorção nas colunas de solo arenoso, evidenciada pelo rápido avanço da frente do soluto. Na distribuição dos cátions, tanto no solo argiloso quanto no arenoso, as curvas têm uma inclinação suave, indicativo de maior interação entre solo-soluto, resultando em maiores valores de $\mathrm{R}_{\mathrm{d}}$. Esse efeito também foi descrito por Matos et al. (2013).

Assim como em outros estudos relacionados à contaminação de solos lateríticos, o cloreto foi sorvido, contrariando seu comportamento comum de traçador em solos de clima de temperado e com predomínio de argilominerais de carga permanente (Basso e Paraguassu, 2006; Leite et al., 2003; Shackelford e Redmond, 1995).

No caso do cobre, os valores de $R_{d}$ estão congruentes com os apresentados por Martinez et al. (2001), em Latossolo Vermelho-Amarelo, álico (LVa), e em Podzólico Vermelho-Amarelo, câmbico (PVc), provenientes de Minas Gerais, com intervalos de $\mathrm{R}_{\mathrm{d}}$ de 8,5 a 4,5 (LVa) e 14,7 a 8,3 (PVc).Esses valores foram obtidos a partir de ensaios de percolação com concentração da solução de 200 mg/L de cobre. 
ITA-ARE - KCI 250

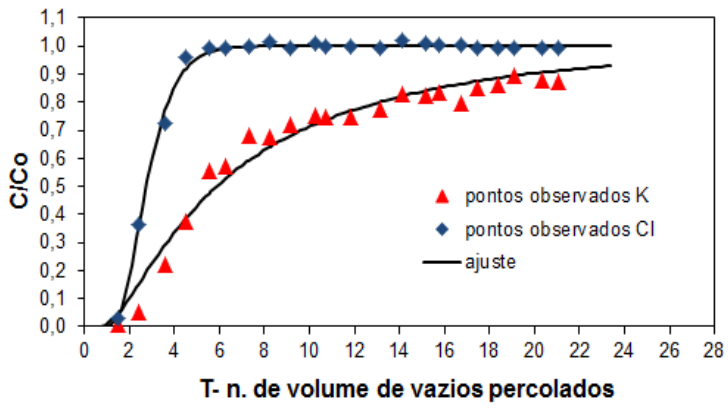

a

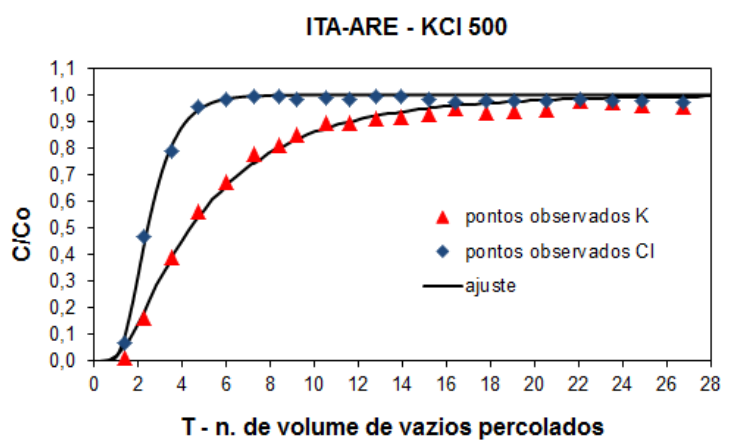

C

ITA-ARE - KCI 1000

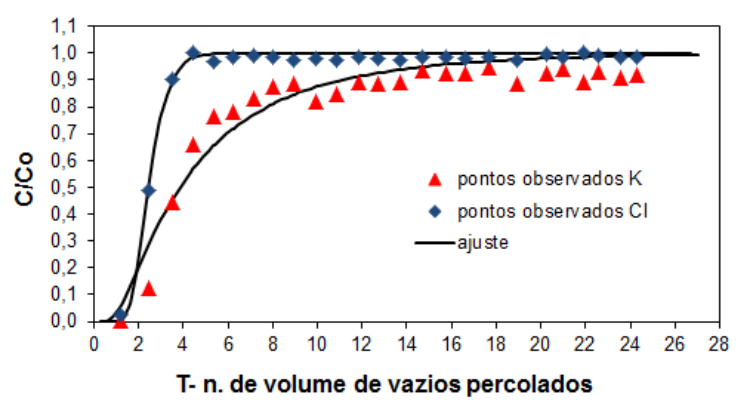

e

Figura 2 - Curvas de Chegada (BTC) de íons em colunas de solo arenoso do Subgrupo Itararé e ajuste do modelo STANMOD. (a), (c), (e) - Ílons K ${ }^{+}$(250 mg/L, $500 \mathrm{mg} / \mathrm{L}$ e $\left.1000 \mathrm{mg} / \mathrm{L}\right)$ e Cl; (b), (d), (f) - Íons Cu ${ }^{2+}$ (250 mg/L, $500 \mathrm{mg} / \mathrm{L}$ e $1000 \mathrm{mg} / \mathrm{L})$ e $\mathrm{Cl}^{-}$.

Figure 2 - Breakthrough curves (BTC) of ions in sandy soil columns of Itarare Subgroup and model fit by STANMOD. (a), (c), (e) - Ions $\mathrm{K}^{+}(250 \mathrm{mg} / \mathrm{L}, 500 \mathrm{mg} / \mathrm{L}$ and $1000 \mathrm{mg} / \mathrm{L})$ and $\mathrm{Cl}^{-}$; (b), (d), (f) - Ion Cu${ }^{2+}(250 \mathrm{mg} / \mathrm{L}$, $500 \mathrm{mg} / \mathrm{L}$ and $1000 \mathrm{mg} / \mathrm{L}$ ) and $\mathrm{Cl}^{-}$. 

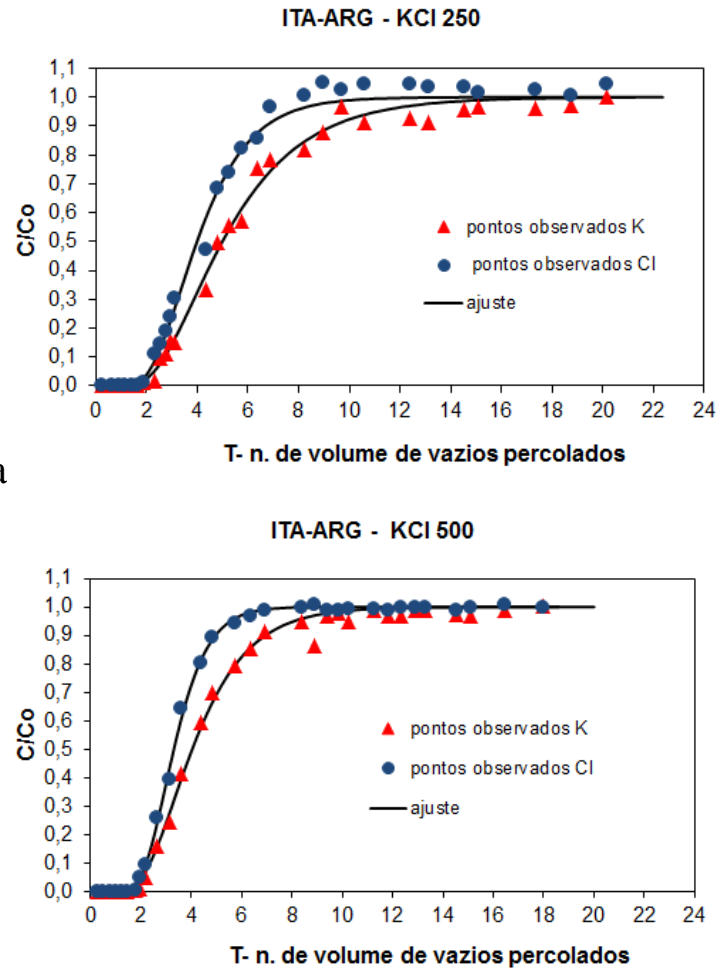

C

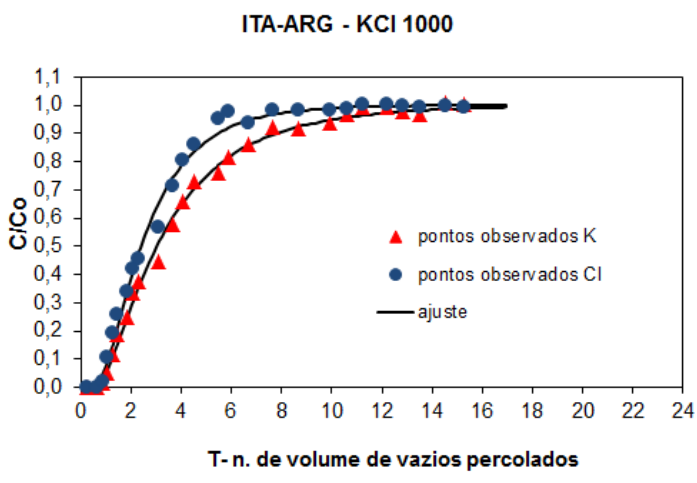

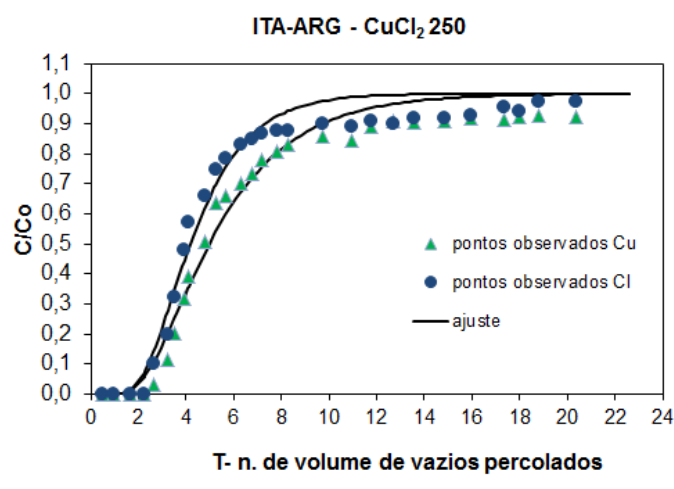

ITA-ARG - $\mathrm{CuCl}_{2} 500$

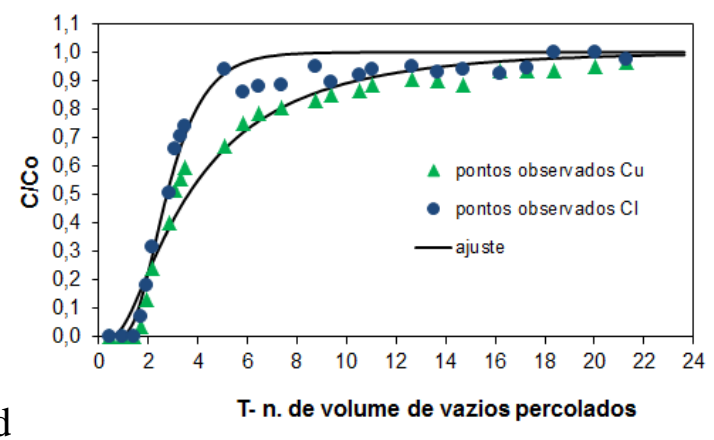

ITA-ARG - $\mathrm{CuCl}_{2} 1000$

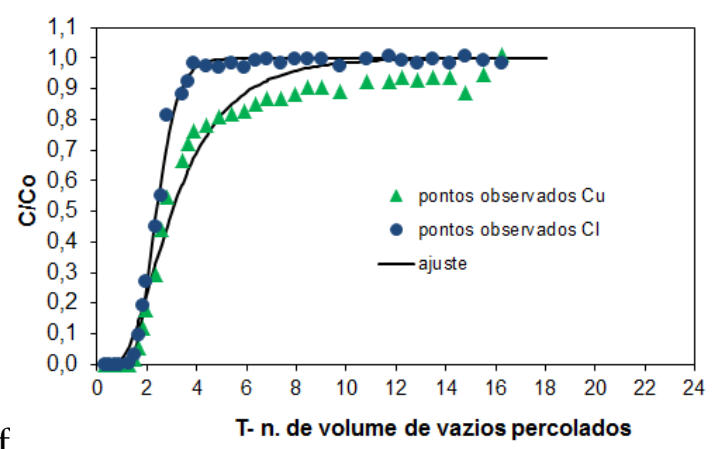

Figura 3 - Curvas de chegada de íons em colunas de solo argiloso do Subgrupo Itararé e ajuste do modelo STANMOD. (a), (c), (e) - Íons K $\mathrm{K}^{+}\left(250 \mathrm{mg} / \mathrm{L}\right.$, $500 \mathrm{mg} / \mathrm{L}$ e $1000 \mathrm{mg} / \mathrm{L}$ ) e Cl-; (b), (d), (f) - Íons $\mathrm{Cu}^{2+}$ (250 mg/L, $500 \mathrm{mg} / \mathrm{L}$ e $1000 \mathrm{mg} / \mathrm{L}$ ) e $\mathrm{Cl}^{-}$.

Figure 3 - Breakthrough curves of ions in clay-rich soil columns of Itarare Subgroup and model fit by STANMOD. (a), (c), (e) - Ions $\mathrm{K}^{+}(250 \mathrm{mg} / \mathrm{L}, 500 \mathrm{mg} / \mathrm{L}$ and $1000 \mathrm{mg} / \mathrm{L})$ and $\mathrm{Cl}^{-}$; (b), (d), (f) - Ion $\mathrm{Cu}^{2+}$ (250 mg/L, $500 \mathrm{mg} / \mathrm{L}$ and $1000 \mathrm{mg} / \mathrm{L}$ ) and $\mathrm{Cl}$.

Yong et al. (1992) mostraram que dentre os diversos metais, o cobre tem grande afinidade de adsorção, tanto em solos minerais (sem ou com pouca matéria orgânica), argilas cauliníticas, óxidos de alumínio, de ferro e de manganês, estando abaixo somente do chumbo. Isto pode ser explicado pela tendência do íon cúprico unirse preferencialmente a ligantes como $\mathrm{OH}^{-}$, $\mathrm{CO}_{3}^{-2}$, e $\mathrm{SO}_{4}^{-2}$, via oxigênio, ou ainda por adsorver-se a vários óxidos e hidróxidos de ferro, alumínio e manganês, comum em solos tropicais. Yu et al. (1997) destacam que os óxidos de ferro, de alumínio e de manganês e suas formas hidratadas são também responsáveis pela adsorção específica de cátions metálicos. Esses óxidos influenciam na adsorção não somente pelo teor, mas também por sua natureza, grau de cristalinidade e pH da solução.

Apesar de o solo argiloso apresentar quantidades superiores de óxidos de ferro, de manganês e de alumínio que o solo arenoso (Tabela 1), nos ensaios de coluna com solo 
argiloso o retardamento do cobre não foi expressivamente superior ao do potássio para justificar a influência desses óxidos na retenção. De certa forma, verificou-se que o retardamento dos cátions foi influenciado pela capacidade de retenção dos argilominerais, sendo consistente com sua baixa capacidade de troca catiônica e área de superfície específica (SE). Assim, a caulinita retém menos que a ilita e menos que a montmorilonita. Também, o maior percentual de matéria orgânica no solo argiloso (Tabela 1) possivelmente contribuiu na retenção do cobre.

Os valores de $R_{d}$ dos cátions no solo arenoso foram superiores aos valores de $R_{d}$ no solo argiloso (Tabela 3). A maior velocidade de avanço da solução nas colunas de material argiloso contribuiu, em parte, para menores valores de $\mathrm{R}_{\mathrm{d}}$, em comparação com o solo arenoso, devido ao menor tempo de interação entre o solo e a solução contaminante (Tabelas 2 e 3). A influência da taxa de fluxo no desempenho da sorção de metais é reportada por Chen et al. (2003). Esses autores afirmam que em altas taxas de fluxo tem-se um menor tempo de contato dos metais nos poros do solo e, por consequência, menor tempo de residência, não sendo suficiente para reagir com o grupo funcional, de forma que a dispersão e a advecção tornam-se fatores importantes na transferência de metais.

$O$ cloreto não segue essa tendência, uma vez que apresentou maiores valores de $R_{d}$ no solo argiloso que no arenoso. No presente estudo, a adsorção de cloreto foi atribuída à caulinita e aos óxidos de ferro e alumínio. A capacidade de troca iônica da caulinita pode ser conferida pela combinação de ligações quebradas nas arestas das partículas, de substituição isomórfica e de cargas superficiais de $\mathrm{H}^{+}$e $\mathrm{OH}^{-}$expostas na superfície desse argilomineral (MITCHELL, 1993). Com exceção da substituição isomórfica, que resulta em cargas negativas permanentes, essas características fazem com que a caulinita dependa do $\mathrm{pH}$ da solução e seu comportamento adsorcivo seja consistente com o modelo de óxidos metálicos (ex. $\left.\mathrm{Fe}_{2} \mathrm{O}_{3}\right)$. A abundância de $\mathrm{H}^{+}$na água intersticial resulta em baixo $\mathrm{pH}$ e a adsorção na interface sólido-líquido gera cargas positivas (sólido- $\mathrm{OH}_{2}{ }^{+1 / 2}$ ), que representam sítios para adsorção do ânion. Outra forma de adsorção do cloreto da solução é simplesmente pela troca de hidroxilas presentes na superfície sólida das partículas do solo.

A figura 4 mostra que o aumento da concentração da solução influente nas colunas resultou na diminuição do fator de retardamento. A influência da concentração iônica no fator de retardamento, consequentemente na sorção, pode ser visualizada nas BTC (Figuras 2 e 3) através das formas das curvas, tendendo ser mais linearizada (função degrau) nas colunas percoladas com concentrações altas e atingindo antecipadamente o valor de $\mathrm{C} / \mathrm{Co}=$ 1.

Tendência semelhante foi encontrada por Basso e Chang (2011), que constataram, a partir de experimentos de batch test, maior eficiência de sorção em solos percolados por soluções de menores concentrações. Chen et al. (2003) afirmam que a quantidade total de locais disponíveis para adsorção dos íons é finita e, havendo sítios de cargas limitados nas partículas sólidas do solo, quanto maior a concentração de íons presentes na solução em percolação mais rápida deverá ser sua saturação iônica nas colunas de solo.

Os valores de $\mathrm{R}_{\mathrm{d}}$ do cloreto nas colunas de solo argiloso também seguiram a tendência de diminuição da sorção com o aumento das concentrações das soluções influentes. Já os valores de $\mathrm{R}_{d}$ para as colunas de solo arenoso foram pouco influenciados pela concentração, ocorrendo pequeno decréscimo com o aumento das concentrações (Tabela 3). 


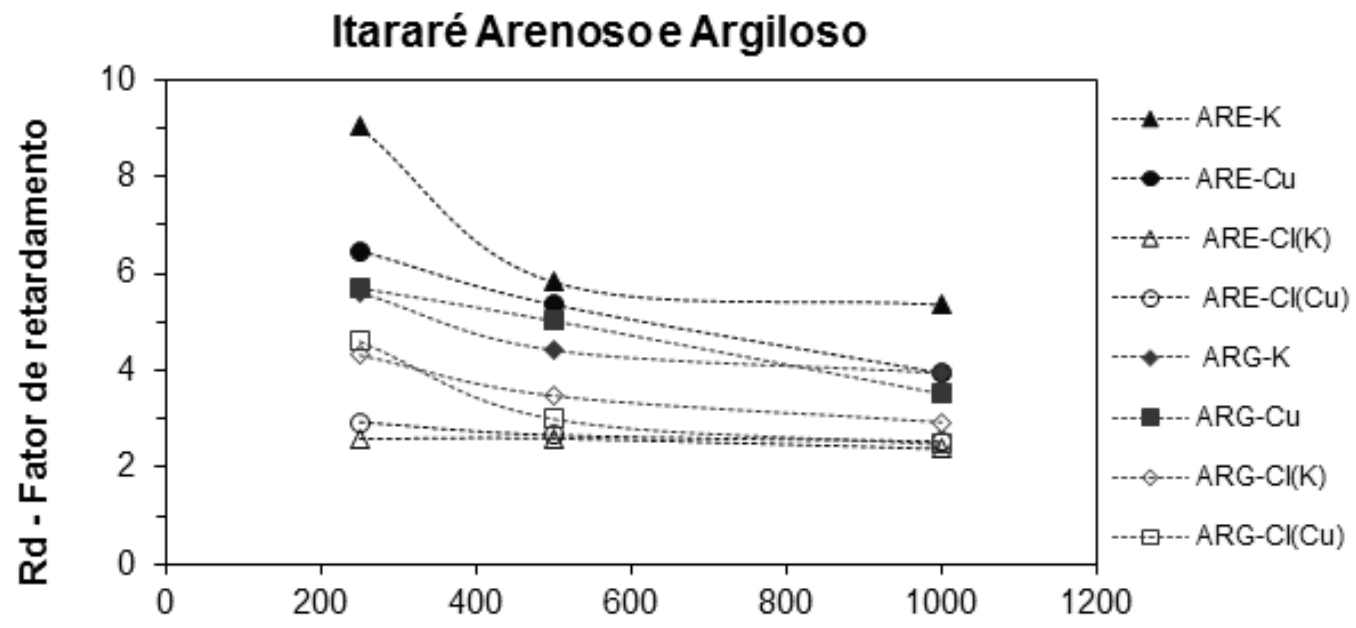

Concentração inicial (mg/L)

Figura 4 - Correlação entre os valores de $\mathrm{R}_{\mathrm{d}}$ (cátions $\mathrm{Cu}$ e $\mathrm{K}$, e ânion $\mathrm{Cl}$ ), em função da concentração do influente nas colunas de solos arenoso e argiloso. Valores de $R_{d}$ obtidos do ajuste do modelo analítico aos pontos experimentais.

Figure 4 - Correlation between $R_{d}$ (cations $\mathrm{Cu}$ and $\mathrm{K}$, and anion $\mathrm{Cl}$ ) values as a function of the initial concentration in sandy and clay-rich soil columns. $R_{d}$ values obtained from the analytical model by fitting to the experimental data.

Os valores de $\mathrm{D}_{\mathrm{h}}$ determinados, tanto para o solo arenoso quanto para o argiloso, foram maiores para os cátions que para o ânion (Figura 5). Essa tendência foi explicada por Shakelford e Redmond (1995), que verificaram que quanto maior o valor de $R_{d}$, maior a magnitude do $\mathrm{D}_{\mathrm{h}}$, de forma a manter valores constantes de $D_{h} / R_{d}$ na equação de transporte de contaminantes, para uma dada concentração de efluente e taxa de fluxo.

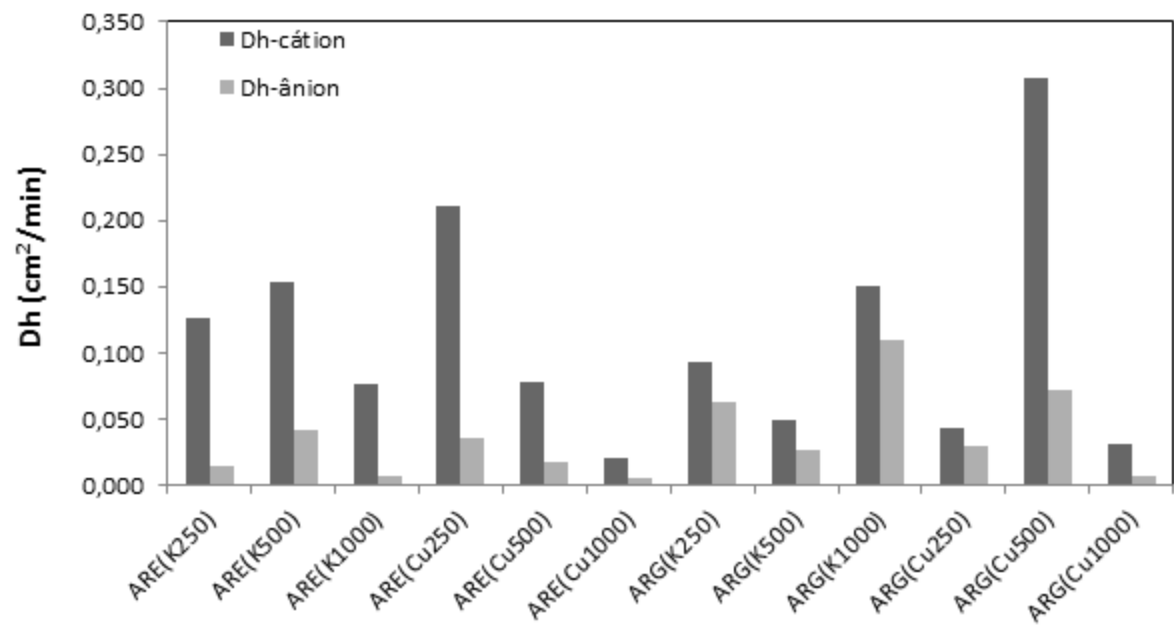

Figura 5 - Gráfico de barras com os valores do coeficiente de dispersão hidrodinâmica para os cátions e ânion das colunas de solos arenoso e argiloso.

Figure 5 - Bar graph showing hydrodynamic dispersion coefficient values of cations $\mathrm{Cu}$ and $\mathrm{K}$, and anion $\mathrm{Cl}$ from sandy and clay soil columns.

Com relação à mineralogia das colunas de solo percoladas com soluções iônicas, a figura 6(a) mostra caulinita e possivelmente ilita (Diagrama a1) indicadas pela ocorrência de $\mathrm{K}^{+}$no arcabouço. A figura 6(b) mostra grãos de quartzo facetados 
envoltos por argilominerais contendo ferro, alumínio e titânio (Diagrama b1). Não foram identificados precipitados de cobre nas análises por EDS de amostras percoladas com soluções de $\mathrm{CuCl}_{2}$; também não foi possível confirmar que a ocorrência de potássio esteja relacionada à precipitação a partir da solução percolante.

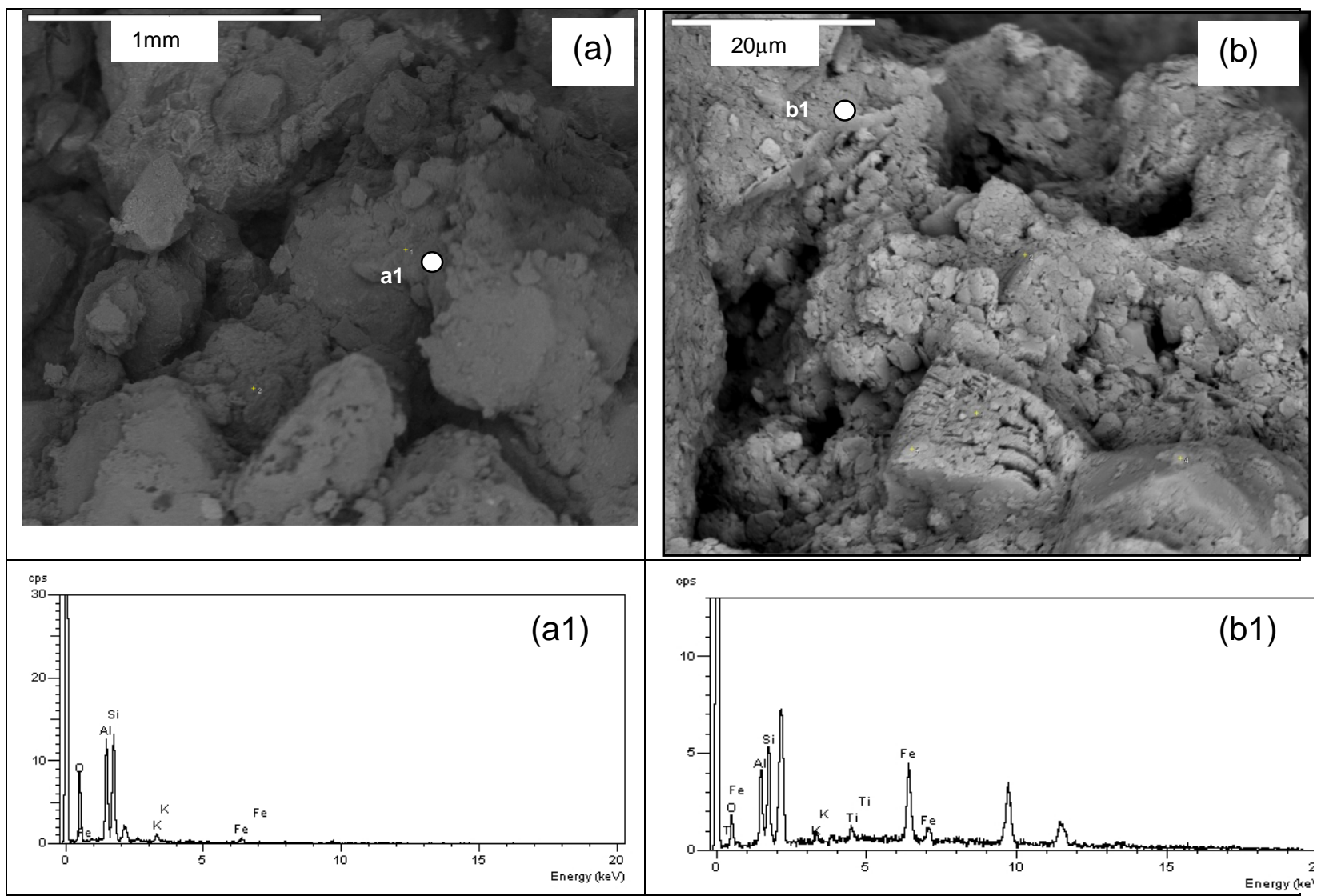

Figura 6 - (a) Fotomicrografia de MEV em amostra da coluna compactada de solo arenoso do Subgrupo Itararé, percolada com solução de $\mathrm{CuCl}_{2} 1000$ mg/L (ampliação de 151 vezes). (b) Fotomicrografia de MEV em amostra da coluna compactada de solo argiloso do Subgrupo Itararé, percolada com solução de $\mathrm{CuCl}_{2} 1000 \mathrm{mg} / \mathrm{L}$ (ampliação de 5000 vezes). (a1) e (b1) Diagramas de composição dos pontos marcados nas fotomicrografias (a) e (b), determinada por EDS.

Figure 6 - (a) SEM photomicrograph of a sample from compacted sandy soil column of Itarare Subgroup percolated by solution of $\mathrm{CuCl}_{2} 1000 \mathrm{mg} / \mathrm{L}$ (magnification 151 times). (b) SEM photomicrograph of a sample from compacted clay soil column of Itarare Subgroup percolated by solution of CuCl $1000 \mathrm{mg} / \mathrm{L}$ (magnification 5000 times) (a1) and (b1) Elemental composition diagrams of the points scored in photomicrographs (a) and (b) determined by EDS.

Embora a precipitação tenha sido induzida com o aumento da concentração dos íons em solução, as condições de pH e Eh e o curto tempo de duração dos ensaios não favoreceram a precipitação dos íons. Reações de precipitação tendem a prevalecer em valores altos de $\mathrm{pH}(>8)$ e a quantidade de metais sorvidos nos solos aumenta. Nas condições de $\mathrm{pH}$ baixo (1 a 4), reações de troca de cátions predominam, os metais ganham mobilidade e a sorção decresce nos solos, devido à competição nos sítios de troca pelo $\mathrm{H}^{+}$.

\section{CONCLUSÕES}

Os íons $\mathrm{Cu}^{2+}, \mathrm{K}^{+}$e $\mathrm{Cl}^{-}$percolados em ensaios de coluna foram adsorvidos pelos solos arenoso e argiloso do Subgrupo Itararé. O ajuste do modelo STANMOD aos dados experimentais foi eficiente e proporcionou a determinação dos parâmetros de $\mathrm{P}$ e $\mathrm{R}_{\mathrm{d}}$.

Nas condições testadas, a velocidade de fluxo nas colunas de solo argiloso foi maior que nas colunas de solo arenoso; também os valores de $\mathrm{R}_{\mathrm{d}}$ dos cátions foram maiores no 
solo arenoso do que no argiloso. Esses resultados sugerem que a adsorção dos cátions foi controlada, sobretudo, pela velocidade de fluxo, e não somente pela quantidade de argila na coluna. Já o cloreto não seguiu essa tendência e apresentou $R_{d}$ maiores nas colunas de solo argiloso; o aumento da concentração iônica influente causou a diminuição do retardamento. A ocorrência de precipitados de cobre e potássio a partir da solução percolante não foi confirmada pelas análises por EDS.

Os resultados permitiram identificar novos valores de fator de retardamento $\left(R_{d}\right)$ e coeficiente de dispersão hidrodinâmica $\left(\mathrm{D}_{\mathrm{h}}\right)$ em solos arenoso e argiloso do Subgrupo Itararé, os quais foram ensaiados em diferentes densidades, resultando em valores de parâmetros de transporte não habituais. Dessa forma, considera-se importante ampliar o conhecimento a partir da aquisição de parâmetros transporte submetidos a diferentes condições de densidade dos solos.

\section{AGRADECIMENTOS}

Os autores agradecem à Fundação de Amparo à Pesquisa do Estado de São Paulo FAPESP (processo $n^{\circ} 05 / 56806-7 R$ ) - e ao Conselho Nacional de Desenvolvimento Científico e Tecnológico - CNPq (processo $\left.\mathrm{n}^{\circ} 140625 / 2006-2\right)$ - pelo apoio financeiro.

\section{REFERÊNCIAS}

ASSOCIAÇÃO BRASILEIRA DE NORMAS TÉCNICAS. Solo. Análise Granulométrica MB 32 (NBR7181), Rio de Janeiro, 1984. 13p.

ASTM. Standard method for specific gravity of soils. American Society For Testing And Materials, ASTM D854, West Conshohocken, PA,1998.

BASSO J.B. Transporte e retenção de $\mathbf{K}^{+}, \mathbf{C u}^{2+}$, e $\mathrm{Cl}^{-}$em uma mistura compactada de solos lateríticos para uso em barreiras selantes: procedimentos de homogeneização e adaptações em equipamento de percolação. Dissertação (Mestrado) - Escola de Engenharia de São Carlos, Universidade de São Paulo.São Carlos, 2003. 168 p.
BASSO J.B., SEIXAS W, PARAGUASSU A.B., CHANG H.K. Fator de Retardamento (Rd) e Dispersão hidrodinâmica (Dh) em mistura de solos das Formações Serra Geral e Botucatu. 2009. In: Congresso Internacional de Meio Ambiente Subterrâneo(CIMAS), São Paulo, I Congresso Internacional de Meio Ambiente Subterrâneo (CIMAS), 2009.

BASSO J.B. Migração de $\mathrm{K}^{+}, \mathrm{Cu}^{2+}$ e $\mathrm{Cl}^{-}$em solos do Subgrupo Itararé no estado de São Paulo: ensaios sorcivos, percolação em colunas e simulações geoquímicas. Tese (Doutorado)Universidade Estadual Paulista, UNESP-Rio Claro Rio Claro, 2010. 189 p.

BEBÉ F.V., ROLIM M.M., PEDROSA E.M.R., SILVA G.B.; OLIVEIRA V.S. Avaliação de solos sob diferentes períodos de aplicação com vinhaça. Revista Brasileira de Engenharia Agrícola e Ambiental. Campina Grande, v.13, n.6, p.781787, 2009.

BRITO F.L; ROLIM M.M.; PEDROSA E.M.R. Teores de potássio e sódio no lixiviado e em solos após a aplicação de vinhaça. Revista Brasileira de engenharia Agrícola e Ambiental, Campina Grande, v.9, (Suplemento), p.52-56, 2005.

BOFF F.E. Avaliação do comportamento de uma mistura compactada de solos lateríticos frente a soluções de $\mathrm{Cu}, \mathrm{K}, \mathrm{Cl}$ em colunas de percolação. Dissertação (Mestrado) - Escola de Engenharia de São Carlos, Universidade de São Paulo. São Carlos, 1999. 180 pp.

CAMARGO, O. A.; MONIZ, A. C.; JORGE, J.A.; VALADARES, J.M.A.S. Métodos de Análise Química, Mineralógica e Física de Solos do Instituto Agronômico de Campinas. Campinas, Instituto Agronômico, 1986. 94 p.

CETESB - COMPANHIA DE TECNOLOGIA E DE SANEAMENTO AMBIENTAL DE SÃO PAULO. Valores orientadores para solos e águas subterrâneas no Estado de São Paulo. Decisão de Diretoria DD 045/2014/E/C/I e DD 330/2014/E/C/I , de 21 de fevereiro de 2014. 4 p. CLEARY, R.W. Qualidade da Água Subterrânea. In: PORTO, R.L.L (org.) Hidrologia Ambiental. São Paulo, EDUSP, p.211-293, 1991.

CONAMA - CONSELHO NACIONAL DO MEIO AMBIENTE. Resolução CONAMA 
n..420, 28 de dezembro de 2009, publicado no D.O.U n 249, de 30/12/2009, p. 81-84, 2009.

EMPRESA BRASILEIRA DE PESQUISA AGROPECUÁRIA. Centro Nacional de Pesquisas de Solos. Manual de métodos de análise do solo. 2 ed. Rio de Janeiro; EMBRAPA SOLOS, 1997. 212p.

EPA (U.S. Environmental Protection Agency). Understanding Variation in Partition Coefficient, $\mathbf{K}_{\mathbf{d}}$, Values. The $\mathrm{K}_{\mathrm{d}}$ Model, Methods of Measurement, and Application of Chemical Reaction Codes, EPA402-R-99-004A, United States Environmental Protection Agency, Washington D.C., volume I, 212p., 1999.

FREEZE, R.A.; CHERRY, J.A. Groundwater. Englewood Cliff. Prentice-Hall, Inc., New Jersey, 1979.

HASSUDA S. Impactos da infiltração da vinhaça de cana no Aqǘfero Bauru. Dissertação (Mestrado) - Instituto de Geociências. Universidade de São Paulo. São Paulo, 1989. 92 p.

LAN, T.N. Um nouvel essai d'identification dês sols: I'essai au bleu de méthylène. Bull. Liaison Lab.Ponts Chaussees, 88, p.136-137, 1977.

LEITE J.C. Estudos laboratoriais de percolação em colunas de misturas de solos lateríticos compactadas: equipamento e ensaios. Tese (Doutorado) - Escola de Engenharia de São Carlos. Universidade de São Paulo. São Carlos, 2000, 223p.,

LEITE A.L. Migração de íons inorgânicos em alguns solos tropicais, com ênfase nos processos de sorção e difusão molecular. Tese (Doutorado) - Escola de Engenharia de São Carlos, Universidade de São Carlos, Universidade de São Paulo. São Carlos, 2001. 254 p,

LEITE, A.L., PARAGUASSÚ, A.B., ROWE, R.K. Sorption of Cd2, K+, F-and Cl- on some tropical soils. Canadian Geotechical Journal. Rev. Can. Geotech, v. 40, n. 3, p. 629-642, 2003.

LEVANTAMENTO PEDOLOGICO SEMIDETALHADO DO ESTADO DE SÃO PAULO. Serviço Nacional de Levantamento e Conservação do Solo. Instituto Agronômico. Quadricula II São Carlos, Memorial Descritivo, Campinas $n^{\circ} 98$, 188p. Escala1:100.000. 1984
LINDSTROM, F.T; HAGUE R; FREED, V.H.; BOERSMA, L. Theory on the movement of some herbicides in soils: linear diffusion and convection of chemicals in soils. Environ. Sci. Technol. V. 1, p. 561-565, 1967.

LUDWIG B.; KOLBL A. (Modelling Cation Exchange in columns of disturbed and undisturbed subsoil. European Journal of Soil Science, Blackwell Science Ltd, v. 53, p. 645-653, 2002.

MARTINEZ M. A.; RAMOS V.B.N; MATOS DE A. T.; OLIVEIRA DE R. A.; COSTA DA S. N. Influência da competição catiônica nos valores de fator de retardamento e coeficiente de dispersãodifusão de zinco e cobre no solo. Revista Brasileira de Engenharia Agrícola e Ambiental, Campina Grande, PB, v. 5, n.2, p.211215, 2001.

MATOS, A. de T., GARIGLIO, A. de A. MONACO, A.V.Lo. Deslocamento Miscível de Cátions Provenientes da Vinhaça em Colunas de Solo. Revista Brasileira de Engenharia Agrícola e Ambiental. Campina Grande, PB, v.17, n.7, p.743-749, 2013.

MITCHELL, J.K. Fundamentals of Soil Behaviour. John Wiley \& Sons, New York, 1993.

MINISTÉRIO DA SAÚDE. Portaria MS N. ${ }^{\circ}$ 2914/ 2011- Dispõe sobre os procedimentos de controle e de vigilância da qualidade da água para consumo humano e seu padrão de potabilidade. 10p.

OGATA A.; BANKS, R.B. A solution of the differential equation of longitudinal dispersion on porous media. US Geol . Surv. Prof. Paper, 411A, 7p., 1961.

OGATA A. Theory of dispersion in a granular medium. US Geol . Surv. Prof. Paper, 411I.,1970.

OLIVEIRA, P.M.; SILVA, A.M.; COELHO, G; SILVA, R.A. Análise comparativa da caracterização físico-hídrica de um latossolo vermelho distrófico in situ e em laboratório. Irriga, Botucatu, v.10, n.1, p.1-19, 2005.

PARAGUASSÚ A.B., BOFF F.E. \& ZUQUETTE L.V. 2002. Laboratorial studies of lateritic residual soils to assess liner's behavior. Geotecnia: Revista da Sociedade Portuguesa, 94, 37-55. 
PEJON, O. P. Mapeamento geotécnico regional da folha de Piracicaba - SP (escala 1:100.000): estudo de aspectos metodológicos, de caracterização e de apresentação de atributos. Tese (Doutorado) - Escola de Engenharia de São Carlos, Universidade de São Paulo. São Carlos. 1992, 224 p. 2v.

PEREIRA, E. M. Interação solo/solução aquosa através de ensaios de percolação em colunas. Relatório de Atividades CNPq - Pós Doutorado. Rio Claro. Universidade Estadual Paulista, 2006. 80 p.

PETRI, S.; VIEIRA, P.C; ODA, G.H.; BOTELHO, P.F. O subgrupo itararé, permocarbonífero da região do médio Tietê, Estado de São Paulo: estudos em subsuperfície. Revista do Instituto Geológico. São Paulo, v. 17, n. 1/2, p. 63-78, 1996.

RAIJ B. van; ANDRADE de J.C.; CANTARELLA H.; QUAGGIO J.A. Análise química para avaliação da fertilidade de solos tropicais, Campinas, Instituto Agronômico, 2001. 285p.

SANTOS, R.S. DA S; SILVA, L. P. DA; MIRANDA, J. H. DE. Obtaining potassium transport parameters using Stanmod model. Soil and Water Engineering. International Conference of Agricultural Engineering - CIGRAgEng2012: agriculture and engineering for a healthier life, Valencia, Spain, 8-12 July 2012; 2012pp. C-1404.

SHACKELFORD, C.D.\& REDMOND, P. L. Solute breakthrough curves for processed kaolin at low flow rates. Journal of Geotechnical Engineering Division, American Society of Civil Engineers, v. 121, n. 1, p.17-32, 1995.

SHACKELFORD, C.D. Contaminant Transport. In :DANIEL, D.E., Ed., Geotechnical Practice for Waste Disposal. London, Chapman \& Hall, chap., p.33-65. 1993.

SILVA, D.P. Influencia da contaminação por cloreto de cobre na resistência ao cisalhamento de solos utilizado em liners. Dissertação (Mestrado) - Escola de Engenharia de São Carlos, Universidade de São Paulo. São Carlos, 2005. 180 p.

ŠIMŮNEK, J.; VAN GENUCHTEN, M.Th.; ŠEJNA, M.; TORIDE, N.; LEIJ, F.J. The STANMOD computer software for evaluating solute transport in porous media using analytical solutions of convection-dispersion equation: version 1.0 and 2.0, U.S. Riverside: USDA, ARS, Salinity Laboratory, 1999. 32 p.

SOTO, M.A.A. Estudo da condutividade hidráulica em solos não saturados. Dissertação (Mestrado) - Escola de Engenharia de São Carlos, Universidade de São Paulo. São Carlos, 1999. 120 pp.

van GENUCHTEN M. Th.; ALVES, W.J. Analytical Solutions of the one-dimensional convective - dispersive solute transport equation. USDA. Tech. Bull. 1661., 1982.

van GENUCHTEN, M. Th.; WIERENGA, P.J. Solute Dispersion Coefficients and Retardation Factors. In: A. Klute (ed.), Methods of Soil Analysis, part 1. Physical and Mineralogical Methods, Agronomy, v. 9, n. 1, p. 1025-1054p. 2nd ed., Am. Soc. Agron., Madison, WI., 1986.

YONG, R.N; MOHAMED, A.M.O.; WARKENTIN, B.P. Principles of Contaminant Transport in Soils. Amsterdam: Elsevier Science Publishers B.V. 327p., 1992.

YU, T.R. Chemistry of variable charge soils. New York/Oxford, Oxford University Press. 1997. $505 \mathrm{p}$. 